\title{
Spinal cord injury due to suicide attempts
}

\author{
F Biering-Sørensen MD PhD, W Pedersen MD, P Giørtz Müller MD
}

Centre for Spinal Cord Injured, Rigshospitalet, Havnevej 25, DK-3100 Hornbaek, Denmark.

\begin{abstract}
During 1965 to 198745 patients were admitted to the Rehabilitation Hospital in Hornbæk, Denmark because of spinal cord injury (SCI) due to suicide attempts. The proportion of traumatic SCI due to this cause increased significantly during the period: $1965-74: 3.5 \%, 1975-84: 8 \%, 1985-87: 13 \%$. The median age at injury was 31 years, and the female to male ratio 1.6 . In 38 instances $(84 \%)$, SCI was caused by jumps from buildings. The neurological level of the lesion was: 7 cervical, 8 thoracic, 22 lumbar; the remaining 8 had minor spinal cord/cauda equina lesions. At the time of the SCI $62 \%$ were unemployed or receiving an early pension; $60 \%$ were living without a partner; $62 \%$ had previously been admitted to psychiatric hospitals, and $31 \%$ had previously attempted suicide.

A follow up study was conducted in 1988-89. At follow up 11 patients had died, 3 from suicide. Of the 34 alive at follow up, 7 had attempted suicide, and 2 reported suicidal thoughts; $71 \%$ were living without a partner; $9 \%$ were employed; $18 \%$ abused alcohol; $44 \%$ had had a psychiatric admission since the $\mathrm{SCI}$; and $56 \%$ were taking psychiatric medication.
\end{abstract}

Key words: spinal cord injury; suicide; attempted suicide; epidemiology.

\section{Introduction}

Suicide attempts leading to spinal cord injury (SCI) have been reported in frequencies between $1.4 \%$ and $5.3 \%{ }^{1-3}$ - several times higher for women than for men.

In recent years we have observed an increase in the number of SCI due to suicide attempts. We felt that it is of interest to look into the problem in greater detail.

\section{Materials and methods}

All records on patients with SCI (including cauda equina syndromes) admitted to the Rehabilitation Hospital in Hornbæk, Denmark in the period 1965-87 were reviewed. From records of patients having SCI following suicide attempts, the following information was extracted: gender, age at injury, cause of injury, level of neurological lesion, employment, cohabitation, housing, drug/ alcohol abuse, previous suicide attempts and admissions to psychiatric hospitals.

A follow up study was conducted during autumn 1988 and spring 1989, information being sought on employment, cohabitation, and the housing situation at the time of follow up; attempted suicides and psychiatric hospitalisation since the SCI; and the use of drugs and alcohol. If the patients had been studied in the Centre for Spinal Cord Injured recently, the follow up information was extracted from the record, otherwise the patient's general practitioner was asked to supply the information.

If the patient was dead at the time of follow up, the cause of death was sought either from medical records or death certificates.

Statistical analyses were carried out using Chi-square and Mann-Whitney rank sum tests. A level of significance of $5 \%$ was chosen.

\section{Results}

During 1965 to 1987657 patients with SCI were admitted to the Rehabilitation Hospital in Hornbæk, Denmark, 45 (6.8\%) due to a suicide attempt. This frequency showed a significant increase $(p=0.0019)$ through 
the years: $1965-74: 3.5 \% \quad(10 / 285)$; 1975-84: $7.8 \%$ (21/286); 1985-87: $13.5 \%$ (14/104).

The overall female to male ratio was 1.6 $(28 / 17)$. The age range at injury was $17-59$ years (median 31 years); for men 17-50 years (median 24 years), and for women 18-59 (median 37 years). The difference between men and women is not statistically significant.

Thirty-eight patients ( $84 \%)$ jumped from buildings: 6 from the first floor, 13 from the second floor, 9 from the third floor, 8 from the fourth floor, one from the fifth floor, and one, a man, from the twelfth floor. Eight of these jumps, of which 6 were by women, occurred during an inpatient period and 6 occurred in psychiatric departments. In addition, 2 jumped from a height: one man from a bridge 20 metres high and one woman from a granary 12 metres high. Two women jumped in front of a train and both suffered from cranial/cerebral lesions, together with a cervical lesion in one and a lumbar cord lesion in the other. Finally, 2 men ran against an armoured glass window, both sustaining cervical lesions, and one shot himself causing a cauda equina lesion, together with intestinal lesions.

The reason for the attempted suicide may be difficult to assess. According to the records, some kind of psychiatric illness or a problem of alcohol or drug misuse was present in 30 instances, and family problems were at least part of the reason in 16 patients. Four said that loneliness, and 2 that economic problems played a part in their decision to attempt suicide.

The highest cranial bony level involved in the spinal column is given in Table I. More than one vertebra was fractured or luxated in 19 out of $43(44 \%)$ patients, and fractures at up to 6 vertebral levels were found.

At the time of discharge from the Rehabilitation Hospital the neurological level of lesion was cervical in 7 patients $(5$ complete lesions), thoracic in 8 (7 complete), and lumbar in 22 (3 complete; 6 motor complete). Seven had regained normal or nearly normal motor function and one was left with a lesion of the lumbar plexus.

Thirty-six patients $(80 \%)$ also had lesions outside the spinal column/cord. Among the 9 without concomitant lesions, 4 had cervical and 4 thoracic injuries. A review of the extraspinal lesions is given in Table II. Multiple lesions were found in most patients, although 12 had only one extraspinal lesion. It should be noticed that calcaneal fractures were often bilateral (10 patients).

Table III gives the marital status of the 45 patients at the time of their injury, together with information on how many had children. Of those living alone, 6 were divorced and one was widowed. Of the 13 patients

Table I The highest cranial bony level of the spine involved in 43 patients with spinal cord lesions caused by attempted suicide. Two patients had no vertebral lesion

\begin{tabular}{lrr}
\hline Most cranial vertebral lesion & No & $(\%)$ \\
\hline Cervical & 8 & $(19)$ \\
Thoracic $1-10$ & 9 & $(21)$ \\
Thoracic 11-12 & 6 & $(14)$ \\
Lumbar I & 11 & $(26)$ \\
Lumbar II & 6 & $(14)$ \\
Lumbar III & 3 & $(7)$ \\
\hline
\end{tabular}

Table II Extraspinal lesions in 36 patients with spinal cord injuries caused by attempted suicide. Nine of the total of 45 patients had no concomitant extraspinal lesion

\begin{tabular}{lc}
\hline Extraspinal lesions & $\begin{array}{c}\text { No of } \\
\text { patients }\end{array}$ \\
\hline Cranial fracture/cerebral contusion & 4 \\
Mandibular fracture & 1 \\
Clavicular fracture & 2 \\
Coastal fracture & 13 \\
Pneumo/hæmothorax & 14 \\
Intra-abdominal lesions* & 5 \\
Iliac, ischial, pubic bone fracture & 11 \\
Sacral fracture & 5 \\
Scapular fracture & 1 \\
Humeral fracture & 5 \\
Antebrachial fracture & 4 \\
Femoral fracture & 2 \\
Crural fracture & 10 \\
Calcaneal fracture & 15 \\
Other lower extremity lesions & 7
\end{tabular}

*include splenic, hepatic, pancreatic and intestinal lesions together with retroperitoneal haemorrhage. 
who were married at the time of injury, 4 were negotiating divorce at the time of their discharge.

The residence and employment situation at time of injury is shown in Tables IV and V. After discharge from the rehabilitation hospital only 9 went back to their previous residence. These include the one who was a resident in the psychiatric hospital and 2 who stayed with their parents. In addition 9 went to a new residence of their own, 7 rented rooms or apartments and 2 to houses. Three were discharged to relatives. Nine were discharged to nursing homes. Fourteen, excluding the one already mentioned, were discharged to other hospitals or departments. Six of these were psychiatric departments, and 4 were hospitals in Greenland. One patient left the hospital before his rehabilitation was completed.
Records reveal that at least 10 patients used antipsychotic drugs and at least 5 used sedatives at the time of their injury. Seven were known drug misusers, 5 using narcotics and 2 diazepam. Fifteen had a large alcohol consumption, and 11 were classified at the time of injury as alcohol misusers.

Of the 45 patients at least 14 had previously attempted suicide, at least 23 attempts in all. In 5 of these attempts, drugs were used and 3 involved cutting the radial artery.

Twenty-eight (62\%) had been admitted to a psychiatric hospital or department prior to the injury, at least 97 admissions in all. Nine had one admission, and one had 11 known admissions. The diagnoses given to those patients who had been admitted to the psychiatric departments prior to the injury is given in Table VI (first column).

Table III Marital and parental status at the time of injury of 45 patients with a spinal cord injury caused by attempted suicide, and marital status for 33 patients at follow up (unknown for one)

\begin{tabular}{lccr}
\hline Marital status & $\begin{array}{c}\text { At time } \\
\text { of injury } \\
\text { No (\%) }\end{array}$ & $\begin{array}{c}\text { No with } \\
\text { child/ } \\
\text { children* }\end{array}$ & $\begin{array}{c}\text { At follow- } \\
\text { up } \\
\text { No (\%) }\end{array}$ \\
\hline Married & $13(29)$ & 11 & $5(15)$ \\
Cohabiting & $5(11)$ & 3 & $5(15)$ \\
Living alone & $27(60)$ & 7 & $23(70)$ \\
\hline
\end{tabular}

*8 had one child, 8 had 2 children, 4 had 3 children, and 1 had 4 children.

Table IV Residence at the time of the injury for 45 patients with spinal cord injury caused by attempted suicide, and for the 34 patients who were alive at the follow up

\begin{tabular}{lrc}
\hline Residence & $\begin{array}{c}\text { At the time } \\
\text { of injury } \\
\text { No (\%) }\end{array}$ & $\begin{array}{c}\text { At } \\
\text { follow-up } \\
\text { No (\%) }\end{array}$ \\
\hline House & $8(18)$ & $5(15)$ \\
Apartment & $20(44)$ & $19(56)$ \\
Rented room & $6(13)$ & - \\
Stay with parents & $6(13)$ & $2(6)$ \\
Sheltered residence & - & $5(15)$ \\
Stay in psychiatric hospital & $1(2)$ & - \\
Nursing homes & - & $3(9)$ \\
No permanent residence & $4(9)$ & - \\
\hline
\end{tabular}


Table V Employment at the time of the injury for 45 patients with a spinal cord injury caused by attempted suicide, and for the 34 patients who were alive at the follow up

\begin{tabular}{lrc}
\hline Employment situation & $\begin{array}{c}\text { At time of injury } \\
\text { No (\%) }\end{array}$ & $\begin{array}{c}\text { At follow up } \\
\text { No (\%) }\end{array}$ \\
\hline Gainfully employed & $10(22)$ & $4(12)$ \\
On sick leave & $1(2)$ & $1(3)$ \\
In education & $3(7)$ & - \\
Housewife & $3(7)$ & - \\
Unemployed & $24(53)$ & $7^{*}(21)$ \\
Early pension & $4(9)$ & $22(65)$ \\
\hline
\end{tabular}

*These were not gainfully employed. Their economical situation was unknown

At least 36 patients $(80 \%)$ were seen by a specialist in psychiatry after hospitalisation. Thirty-three were given the diagnoses listed in Table VI (second column). When comparing the preinjury and immediate postinjury diagnoses in Table VI it should be noted that 12 patients had the same diagnoses before and after injury; 10 had different preinjury diagnoses; and 11, without a preinjury diagnosis, were given one after injury. Information concerning 6 patients with a preinjury diagnosis was not available after their injury.

At least 20 of the 45 patients were given immediate psychiatric follow up after discharge from the rehabilitation hospital.

\section{Follow up}

At the time of follow up 11 (ie $24 \%$ ), 6 women and 5 men, were reported to have died. At the time of death their median age was 43 years (range 27-72 years), and the median duration since the SCI was 8 years (range 8 months -17 years). These patients included 2 with cervical cord lesions, who were discharged to nursing homes after rehabilitation. One patient with thoracic lesion was transferred to a psychiatric hospital after rehabilitation. The remainder had lumbar lesions (6 patients), or were neurologically nearly normal after rehabilitation. Of these 4 were transferred to a psychiatric hospital, one to a nursing home, and 2 to stay with relatives. Only one, a man, went back to his own home and wife.

In 3 instances the cause of death was suicide. One jumped from the third floor, one jumped in front of a train, and one drowned himself. At the time of suicide, 2 of these patients were inpatients in psychiatric hospitals and the third was in psychiatric treatment.

Seven of the deaths were probably due to natural causes. Two patients with cervical lesions died because of respiratory complications, and the patient with the thoracic injury had uraemia, having had a nephrotic syndrome for 3 years. One patient with chronic alcoholism died of acute pancreatis with peritonitis. Two women aged 57 and 72 years probably died of arteriosclerotic heart disease, whilst one patient, 41 years old, was found dead in his home with no signs of suicide or violence.

One patient died outside Denmark, and the cause of death is unknown.

The follow up period for the remaining 34 patients was $1 \frac{1}{2}-21$ years (median 7 years).

At follow up 23 lived alone, including 2 who stayed with their parents (Table III).

The residence at follow up is seen in Table IV.

Only 4 patients were gainfully employed at follow up. Two had office jobs, one was assistant at a library, and one was teaching in high school (Table V). It seems likely that some of the 7 registered as unemployed in Table $\mathrm{V}$ received an early pension or some sort of allowance.

Since the original injury, at least 7 had made further attempts of suicide, 2 more than once. Two patients had taken an overdose of tablets, 3 had cut themselves 
Table VI Psychiatric diagnoses given to: (1) 28 patients with spinal cord injury (SCI) caused be attempted suicide, who prior to the injury were admitted to psychiatric department; (2) 33 patients after their SCI caused by attempted suicide; and (3) 20 patients who at the follow up still were taking psychiatric medication. The diagnoses are grouped in accordance with the International Classification of Diseases (8th ed.)

\begin{tabular}{|c|c|c|c|}
\hline Diagnosis & $\begin{array}{c}\text { *Prior to SCI } \\
\text { N }=28 \\
\text { No }\end{array}$ & $\begin{array}{c}\text { + Just after SCI } \\
\mathrm{N}=33 \\
\text { No }\end{array}$ & $\begin{array}{c}{ }^{++} \text {At follow up } \\
\mathrm{N}=20 \\
\text { No }\end{array}$ \\
\hline \multicolumn{4}{|l|}{ Psychoses } \\
\hline Abstinence & 1 & & \\
\hline Schizophrenic & 6 & 6 & 5 \\
\hline Manic depressive & 1 & 3 & 5 \\
\hline Paranoid & 3 & 2 & \\
\hline Reactive & 8 & 11 & 3 \\
\hline \multicolumn{4}{|l|}{ Neuroses } \\
\hline Anxiety & 1 & 1 & \\
\hline Hysteric & 1 & 1 & \\
\hline \multicolumn{4}{|l|}{ Personality disorders } \\
\hline Borderline personality & 1 & 5 & \\
\hline Psychopath personality & & 2 & \\
\hline Psychoinfantility/ & & & \\
\hline $\begin{array}{l}\text { impulsive emotional } \\
\text { lability }\end{array}$ & & 3 & \\
\hline Character neuroses & 6 & 3 & 4 \\
\hline Reserved nature & & 1 & \\
\hline Alcohol addiction & 1 & 1 & 2 \\
\hline Drug addiction & 3 & 1 & 2 \\
\hline
\end{tabular}

*Four patients had 2 diagnoses

+ Five patients had 2 diagnoses and one 3 diagnoses

${ }^{++}$One patient had 2 diagnoses

with a knife, one jumped from the third floor, and one drove his wheelchair over a slope. In addition to those who had attempted suicide 2 had had repeated suicidal thoughts.

At follow up at least 6 misused alcohol and 3 drugs. One patient has misused both. In addition, at least 20 were taking psychotropic medication, and at least 15 been admitted to psychiatric hospitals or departments. For the patients on continous psychotropic medication the diagnoses were recorded as shown in Table VI.

\section{Discussion}

The reason for the increase in the frequency of SCI due to attempted suicide within the last years is not known, but Jensen et $a l^{4}$ summarised the literature on suicide attempt and found such attempts to be on the increase, not least for poisoning. One might therefore assume that this trend is the same for our population. This tendency was also observed by Hoff and Chapman ${ }^{5}$ in their study on vertebral fractures associated with suicide attempts and they ascribed the increase to the prevalence of drug abuse among members of the so-called beat generation. No other published materials have shown frequencies as high as the $13 \%$ we found for SCI caused by attempted suicide in the period 1985-87. On the other hand the predominence of women in this group is well established ${ }^{1-3}$ in contrast to the opposite pattern for traumatic SCI in general. ${ }^{6}$ Previous Danish work on attempted suicide ${ }^{4,7.8}$ has shown a similar male/female 
ratio around 0.5 , and an average age of 40 years, which is somewhat higher than our median age of 31 years, but of the same magnitude as that found by Girard et al.$^{2}$ It is interesting to note that in a study of all suicides in Denmark in $1972^{9}$ more suicides occurred among men than women, and the suicide rate increased with age to a maximum at the age of 50-59 years. In addition they found that men were inclined to use violent methods of suicide, including shooting, and jumping in front of a train. This contradicts our findings, but we may have 2 different forms of behaviour when considering suicide attempts. ${ }^{9,7}$ Kuhn et al $^{3}$ considered the suicide attempts to be of appellatory nature or a 'cry for help'. This is confirmed by the fact that, of our cohort, 19 jumped from the first or second floor. Those who jumped from the highest levels were men. Jumping was the major cause of SCI due to attempted suicide, which is confirmed by previous studies. ${ }^{1-3,10}$ Likewise it has also been established that in the case of a fall on to the feet ${ }^{5,10}$ the resulting lesion is most often at the thoraco-lumbar level, often with coincidental injuries of the extremities, in particular of the calcaneal bone. Cervical lesions caused by running against an armoured glass window in an attempted suicide seem not to have been reported previously.
As already mentioned it is difficult to find the exact reasons which leads a person to attempt suicide, but it is noteworthy that, at the time of attempted suicide, 6 were inpatients in psychiatric departments, 28 had previously been admitted to psychiatric departments, and at least 14 had previously attempted suicide. Finally, 7 abused drugs and 11 misused alcohol. This suggests that most of these individuals already had serious problems when they attempted suicide. In addition $60 \%$ were living alone, although this fact might be associated with their psychological condition. These conditions are similar to those noted by Lærum et $a l^{9}$ among those who committed suicide. Likewise Hoff and Chapman ${ }^{5}$ found an unusually high prevalence of mental illness and drug abuse among those with spinal fractures after suicide attempts.

The situation of the patients does not change after injury, although their physical disability has now to be added to their previous psychic disability. It is not surprising that 3 committed suicide after SCI, since suicide has been found to be one of the leading causes of death for patients with spinal cord injuries in general. ${ }^{11}$

It is difficult to find a solution for this group of patients, but as Kuhn et al ${ }^{3}$ pointed out, it is of the outmost importance that they receive specialist psychiatric care.

\section{References}

1 Chen CF, Lien IN (1985) Spinal cord injuries in Taipei, Taiwan 1978-1981. Paraplegia 23: 364-370.

2 Girard R, Boisson D, Depassio J, Boucand MH, Eyssette M (1983) The female paraplegic: a statistical survey. Paralegia 21: 149-153.

3 Kuhn W, Zäch GA, Köchlin P, Urwyler A (1983) Comparison of spinal cord injuries in females and males, 1979-1981, Basle. Paraplegia 21: 154-160.

4 Jensen S, Lærum H, Rasmussen S, Sørensen T (1975) Medicinal poisoning. Analysis of 102 consecutive cases for deliberate self-poisoning admitted to a medical department. Ugeskrift for lager 137: 1247-1253 (Danish with summary in English).

5 Hoff J, Chapman M (1972) Vertebral fractures associated with suicide attempts. Proceedings of the 18th Veteran Administration meeting, Boston: 53-55.

6 Biering-Sørensen F, Pedersen W, Clausen S (1990) Epidemiology of spinal cord lesions in Denmark. Paraplegia 28: 105-118.

7 Pærregaard G (1963) Attempted suicide and suicide in Copenhagen. Thesis, Copenhagen (Danish with summary in English).

8 Udsen P (1966) Prognosis and follow-up of attempted suicide. Anaesthesiol Clin 4: 379-388.

9 Lærum H, Sørensen T, Rasmussen S (1980) Suicide in Denmark. An analysis based upon the total number of suicides in 1972. Ugeskrift for laeger 142: 37-41 (Danish with summary in English).

10 Girard R, Minaire P, Castanier M, Berard E, Perrineriche B (1980) Spinal cord injury by falls: comparison between suicidal and accidental cases. Paraplegia 18: 381-385.

11 DeVivo MJ, Kartus PL, Stover SL, Rutt RD, Fine PR (1989) Cause of death for patients with spinal cord injuries. Ach Intern Med 149: 1761-1766. 